\title{
Pressure palsy of the ulnar nerve with prolonged conduction block
}

\author{
M. J. G. HARRISON \\ From the Department of Neurological Studies, The Middlesex Hospital, London
}

SYNOPSIS A patient is described in whom conduction block occurred in the ulnar nerve after a pressure palsy and persisted for 16 weeks. The unusually long delay in recovery is discussed.

There have been surprisingly few electrophysiological studies of pressure palsies in man. Trojaborg (1970) reported the findings in a group of patients with different types of radial nerve injury. In 29 cases the lesion was due to pressure during sleep. Trojaborg confirmed that the nerve remained normally excitable below the lesion and inexcitable above, a situation found experimentally by Denny-Brown and Brenner (1944) to be due to local demyelination at the site of nerve pressure. Trojaborg found that clinical recovery occurred in six to seven weeks with restoration of conduction in the radial nerve.

Recent experimental work in the baboon (Fowler et al., 1972; Ochoa et al., 1972) has shown that tourniquet palsies may be accompanied by a more prolonged conduction block, and Rudge (1974) has described a patient in whom conduction block lasted for 16 weeks after a tourniquet lesion of the median and ulnar nerves. That a similar delay in recovery due to prolonged conduction block can occur after a pressure palsy has been demonstrated by a recently studied patient.

\section{CASE REPORT}

J.M., a 29 year old business man, awoke with weakness of his right (dominant) hand. He was first seen one week later. Examination on that occasion revealed weakness (MRC grade 4) of all ulnar supplied muscles including flexor carpi ulnaris and flexor digitorum profundus. There was sensory disturbance in the ulnar territory with a two point

(Accepted 15 August 1975.) threshold of $1.5-2 \mathrm{~cm}$ over the medial $1 \frac{1}{2}$ fingers. There was no evidence of a generalized peripheral neuropathy. The patient was reviewed frequently until full functional recovery had occurred (20 weeks). He was then able to rock climb with no residual weakness in the fingers. Wasting was never obvious at any stage.

ELECTROPHYSIOLOGICAL STUDIES At each visit, the ulnar nerve was stimulated at the wrist, elbow, and in the upper arm. The muscle action potential (map) evoked in abductor digiti minimi was recorded by surface electrodes. A sensory nerve action potential was recorded from the ulnar nerve at the wrist during stimulation of the digital nerves in the little finger (Gilliatt and Sears, 1958). A mixed nerve action potential was recorded from the ulnar nerve at the elbow during stimulation at the wrist (Gilliatt and Thomas, 1960).

\section{RESULTS}

The initial examination revealed a complete conduction block in the upper arm. The ulnar nerve was inexcitable higher than a point $2.5 \mathrm{~cm}$ above the cubital tunnel. Below this, the evoked MAP in the abductor digiti minimi measured $7.8 \mathrm{mV}$ from the point of the elbow and $10 \mathrm{mV}$ from the wrist. The motor conduction velocity (elbow to wrist) was 54 $\mathrm{m} / \mathrm{s}$ (normal $49.0-65.6 \mathrm{~m} / \mathrm{s}$, Thomas et al., 1959), the sensory action potential was $17 \mu \mathrm{V}$ (normal range 8-28 $\mu \mathrm{V}$, Gilliatt and Sears, 1958), and the wrist to elbow volley $30 \mu \mathrm{V}$ (normal range 33-117 $\mu \mathrm{V}$, Gilliatt and Thomas, 1960).

The finger to wrist sensory action potential was measured three weeks later and its amplitude was $17 \mu \mathrm{V}$. Motor conduction velocity (elbow to wrist) remained between 50 and $54 \mathrm{~m} / \mathrm{s}$ throughout. The motor conduction velocity in the upper arm was 


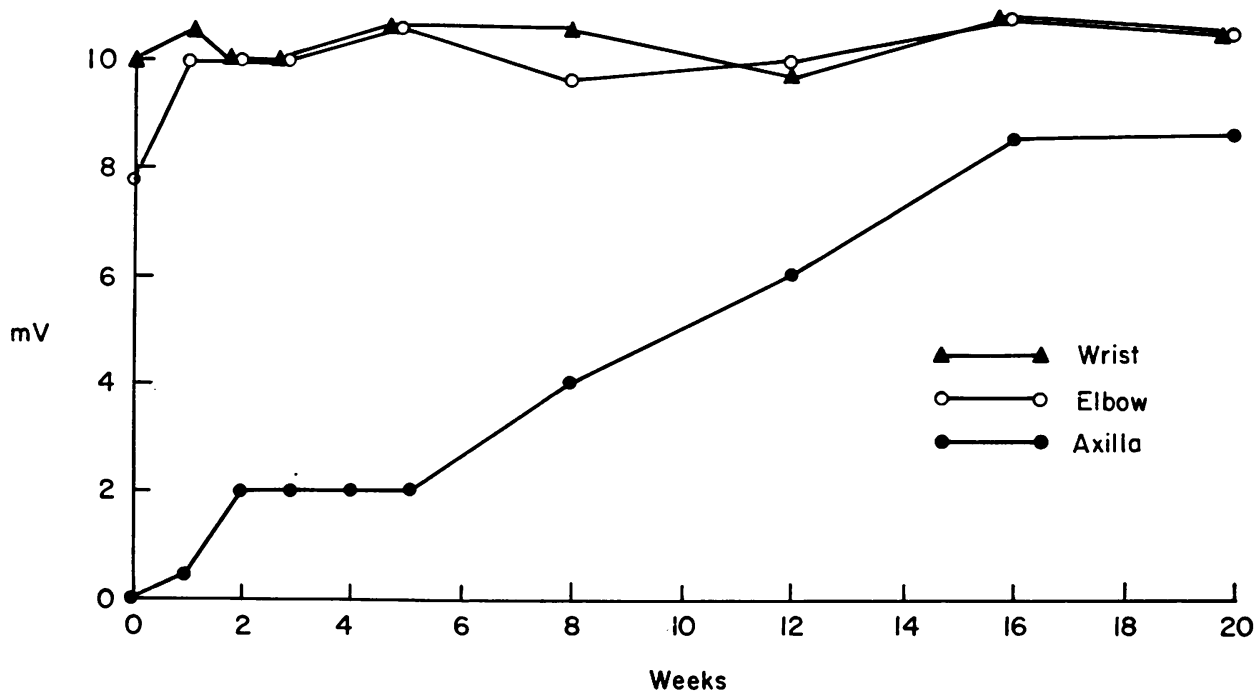

FIG. 1. Amplitude of the muscle action potential recorded from the abductor digiti minimi after stimulation of the ulnar nerve at the wrist, elbow, and in the upper arm.

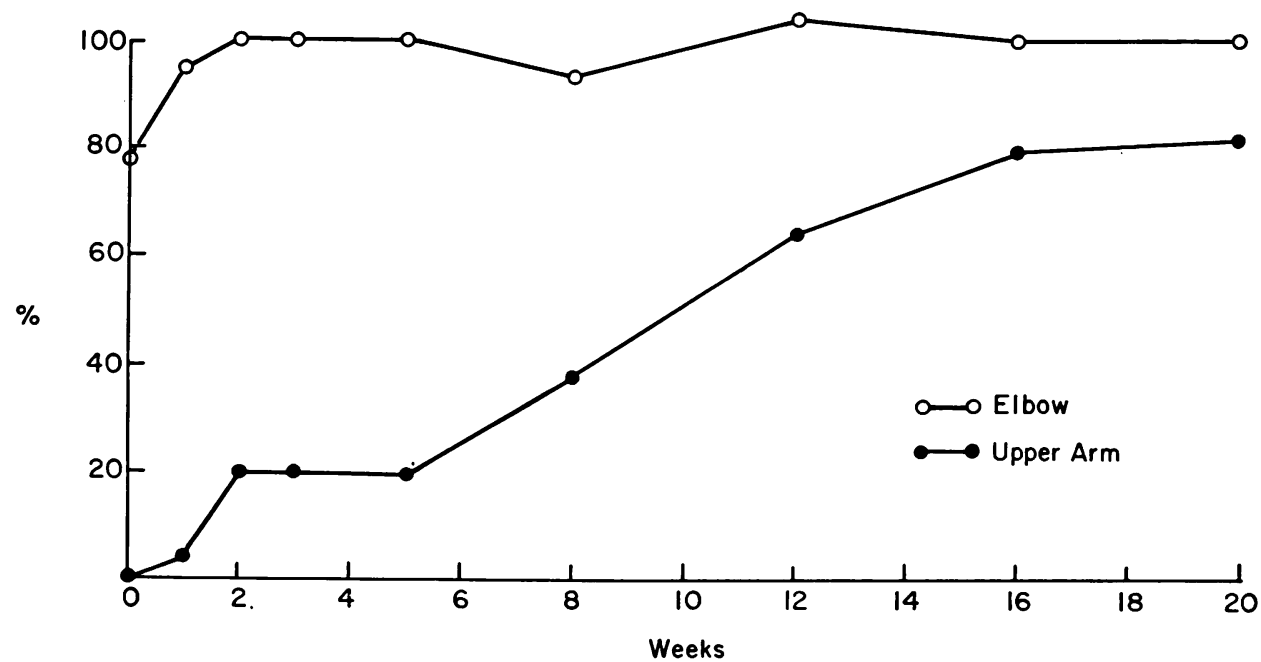

FIG. 2. Amplitude of the muscle action potential (abductor digiti minimi) after stimulation of the ulnar nerve at the elbow and in the upper arm expressed as a percentage of that obtained by stimulation at the wrist. 
first accurately obtained eight weeks from onset and measured $44 \mathrm{~m} / \mathrm{s}$. At the last examination at 20 weeks this had increased to $51.6 \mathrm{~m} / \mathrm{s}$ (normal range $50.0-73.9 \mathrm{~m} / \mathrm{s}$, Gilliatt and Thomas, 1960).

The muscle action potential from abductor digiti minimi was recorded at one, two, three, four, five, eight, 12 16, and 20 weeks after the onset (Figs 1 and 2).

\section{DISCUSSION}

The lack of muscle wasting, and the normal motor and sensory conduction distal to the lesion suggest that little or no Wallerian degeneration occurred in this patient. The lesion appears to have been a neurapraxia (Seddon, 1943) in which local demyelination and remyelination account for conduction block (Seddon, 1943; Denny-Brown and Brenner, 1944; Fowler et al., 1972). The unusual feature of this patient was the long duration of conduction block which normally lasts a shorter interval of approximately six weeks (Trojaborg, 1970).

There are several possible explanations for the long duration of conduction block. Firstly, it is possible that repeated trauma interrupted recovery. This seems unlikely, since the patient was alerted to the risk and the curves of Figs. 1 and 2 do not show a striking break in recovery. Secondly, it might be argued that acute trauma had precipitated symptoms in a chronically damaged nerve. Neary et al. (1975) have recently demonstrated the presence of subclinical entrapment neuropathy of the ulnar nerve in the cubital tunnel in asymptomatic individuals at necropsy. Also, Payan (1970) pointed out that patients with entrapment of the ulnar nerve at the elbow might give a history of the sudden onset of an ulnar palsy. The electrophysiological studies of this patient, however, clearly showed that the lesion was in the upper arm well above the usual site of entrapment in the cubital tunnel. Also, there was no evidence of a chronic neuropathy.

Finally, experimental studies in the baboon have shown possible pathological explanations for prolonged block. Fowler et al. (1972) produced a mechanical lesion of peripheral nerves by tourniquet compression. Under each edge of the cuff, nodes were displaced causing stretching of myelin on one side and invagination of the other. Periaxonal oedema was striking in animals in which conduction block persisted for 20 weeks or more (Ochoa et al., 1972). A narrow ligature produced a similar mechanical distortion of myelin (Rudge et al., 1974), but conduction block was of much shorter duration (six weeks). These data would suggest that a long lesion of the nerve or persistent oedema might be responsible for a more prolonged block. The initial re- duction in muscle action potential with stimulation at the elbow in this patient would support the idea that the nerve was initially damaged over a long course. The recovery curves might be interpreted as showing a sequential recovery of populations of nerve fibres suffering from a spectrum of pathological changes (Gilliatt, 1975).

The technique of recording the amplitude of the muscle action potential of a distal muscle during stimulation above and below the site of the lesion is valuable. It helps to localize the lesion, in this case away from a site of chronic entrapment. Also, it makes it possible to monitor recovery. The demonstration of persistent conduction block was valuable in the present case, as the continuing weakness and clinical localization to the elbow might otherwise have prompted consideration of surgical decompression or transposition of the ulnar nerve (Payan, 1970). The same methods of following recovery were also used by Rudge (1974) in the case of prolonged conduction block after tourniquet palsy.

As well as being of theoretical interest, this case also confirms that delayed recovery can occur after 0 a pressure palsy which has shown little or no return in the first four to six weeks.

I am grateful to Professor R. W. Gilliatt, Dr T. Fowler and Dr P. Rudge for helpful discussions, and to Dr D Williams for referring the patient.

\section{REFERENCES}

Denny-Brown, D., and Brenner, C. (1944). Paralysis of nerve induced by direct pressure and tourniquet. Archives of Neurology and Psychiatry, 51, 1-26.

Fowler T. J., Danta, G., and Gilliatt, R. W. (1972). Recovery of nerve conduction after a pneumatic tourniquet: observations on the hind limb of the baboon. Journal of Neurology, Neurosurgery, and Psychiatry, 35, 638-647.

Gilliatt, R. W., and Sears, T.A. (1958). Sensory nerve action potentials in patients with peripheral nerve lesions. Journal of Neurology, Neurosurgery, and Psychiatry, 21, 109-118.

Gilliatt, R. W., and Thomas, P. K. (1960). Changes in nerve conduction with ulnar lesions at the elbow. Journal of Neurology, Neurosurgery, and Psychiatry, 23, 312-320.

Gilliatt, R. W. (1975). Peripheral nerve compression and entrapment. Proceedings of the Royal Society of Medicine. (In press.)

Moldaver, J. (1954). Tourniquet paralysis syndrome. Archives of Surgery, 68, 136-144.

Neary, D., Ochoa, J., and Gilliatt, R. W. (1975). Subclinical entrapment neuropathy in man. Journal of Neurological Sciences, 24, 283-298.

Ochoa, J., Fowler, T. J., and Gilliatt, R. W. (1972). Anatomical changes in peripheral nerves compressed by a pneumatic tourniquet. Journal of Anatomy, 113, 433-455.

Payan, J. (1970). Anterior transposition of the ulnar nerve: an electrophysiological study. Journal of Neurology, Neurosurgery, and Psychiatry, 33, 157-165. 
Rudge, P. (1974). Tourniquet paralysis with prolonged conduction block. Journal of Bone and Joint Surgery, 56B, 716-720.

Rudge, P., Ochoa, J., and Gilliatt, R. W. (1974). Acute peripheral nerve compression in the baboon. Journal of Neurological Sciences, 23, 403-420.

Seddon, H. J. (1943). Three types of nerve injury. Brain, 66, 237-288.
Thomas, P. K., Sears, T. A., and Gilliatt, R. W. (1959). The range of conduction velocity in normal motor nerve fibres to the small muscles of the hand and foot. Journal of Neurology, Neurosurgery, and Psychiatry, 22, 175-181.

Trojaborg, W. (1970). Rate of recovery in motor and sensory fibres of the radial nerve: clinical and electrophysiological aspects. Journal of Neurology, Neurosurgery, and Psychiatry, 33, 625-638. 